\title{
PRAÇAS PÚBLICAS E PLANEJAMENTO NO MUNICÍPIO DE CAMPOS DOS GOYTACAZES/RJ
}

\author{
PUBLIC SQUARES AND PLANNING IN THE MUNICIPALITY OF CAMPOS DOS \\ GOYTACAZES, RIO DE JANEIRO STATE, BRAZIL
}

\begin{abstract}
Resumo: Este artigo tem como objetivo analisar a forma como as praças públicas de Campos dos Goytacazes/RJ vêm sendo tratadas pelo planejamento urbano municipal. Tendo em vista a complexidade e multiplicidade de interesses que passaram a permear a produção do espaço urbano com a consolidação do sistema capitalista e, no caso do município de Campos dos Goytacazes, das transformações que fazem parte de sua história, acredita-se que reflexos se sucederam nos espaços livres públicos como um todo, mas, sobretudo, nas praças. Para a obtenção de tais respostas, foram realizadas pesquisas bibliográficas e documentais as quais possibilitaram o embasamento teórico deste artigo e o levantamento de dados referentes ao planejamento. Os resultados apontam possíveis falhas do planejamento, acarretando problemas, como concentração de praças em determinadas áreas privilegiadas; tendência de homogeneização dos espaços; inexistência de um estudo visando compreender as potencialidades e limitações dos espaços e, especialmente, os anseios da população; e dificuldade generalizada de garantir a manutenção e preservação das praças. Indicam ainda iniciativas interessantes que vêm sendo adotadas, as quais possuem potencial de fortalecer ainda mais a relação entre a população e os espaços livres públicos da cidade.
\end{abstract}

Palavras-Chave: Espaços Livres. Paisagem. Produção do Espaço.

\begin{abstract}
This article aims at analyzing the way in which public squares of the municipality of Campos dos Goytacazes, Rio de Janeiro State, Brazil has been addressed by municipal urban planning. Given the complexity and diversity of interests that have permeated the creation of urban space with the strengthening of the capitalist system and, in the case of the municipality of Campos dos Goytacazes, the changes that are part of its history, it is believed that successive effects have taken place in public spaces as a whole, especially in squares. To obtain such answers, bibliographical and documentary researches were carried out - which enabled the theoretical basis of this article and the collection of data related to planning. Results indicate possible planning failures, causing problems, such as concentration of squares in certain privileged areas; tendency of homogenization of spaces; lack of a study to understand the potentialities and limitations of spaces and especially the aspirations of the population; and general difficulty of guaranteeing the maintenance and preservation of squares. They also indicate interesting initiatives that have been adopted, which have the potential to further strengthen the relationship between the population and the city's public spaces.
\end{abstract}

Keywords: Public Spaces. Landscape. Production of Space.

Ana Paula Pereira de Campos Lettieri

Mestre em Planejamento Regional e Gestão de Cidades - UCAM; doutoranda em Políticas Sociais (UENF). Professora do Instituto Federal Fluminense - campus Campos Centro; Rua Doutor Siqueira, 273, Parque Dom Bosco, Campos dos Goytacazes, RJ, Brasil, CEP: 28030-130.

Valdir Júnio dos Santos

Pós-doutor em Políticas Sociais pela Universidade Estadual do Norte Fluminense (UENF). Professor do Programa de Pós-Graduação em Planejamento Regional e Gestão de Cidades da Universidade Candido Mendes (UCAM). Pesquisador do Centro de Pesquisa Candido Mendes (CEPECAM), rua Anita Pessanha, 100, Parque São Caetano, Campos dos Goytacazes, Brasil, CEP: 28030-130. 


\section{Introdução}

As praças públicas, desde os seus primórdios, configuram-se como elementos de grande importância para as cidades e seus moradores, independentemente da forma ou das funções por elas assumidas ao longo do tempo em decorrência das transformações vividas pela sociedade. No entanto, com a efetivação do capitalismo, com seu avanço e sua consolidação no território global, a produção do espaço urbano ganha outra dimensão, passando a ser incorporada à lógica de reprodução do referido sistema (CARLOS, 2011).

Nesse contexto, diante da necessidade constante e incessante de expandir-se, o processo de acumulação passa, inevitavelmente, a incorporar o espaço, o qual adquire atributo de mercadoria (HARVEY, 2005). Sob esta nova ótica, a paisagem urbana passa a ser moldada de forma muito mais complexa, envolvendo conflitos de interesse entre o capital e o social e, para além disso, os interesses dos diversos agentes produtores envolvidos - Estado, mercado imobiliário e população (ALVAREZ, 2015).

Diante deste cenário, o planejamento urbano possui relevante papel no que concerne aos espaços públicos urbanos, sua produção, sua conservação, seu uso, entre outros aspectos. Tomando-se como pressuposto as novas questões urbanas, que envolvem a competitividade, o planejamento estratégico e o marketing urbano, nota-se que, muitas vezes, os investimentos nesta tipologia de espaços não se dão de forma homogênea ou igualitária, privilegiando intencionalmente determinadas áreas (e grupos sociais) em detrimento de outras.
Neste sentido, segundo Maricato, o planejamento aplica-se na cidade formal/legal, enquanto para a cidade ilegal/informal não há planos nem ordem, afirmando que a legislação desconsidera a existência de uma parcela da população que vive na ilegalidade no que diz respeito à habitação e à ocupação da terra, excluindo-os socialmente e favorecendo pequenos interesses corporativos (MARICATO, 2002). A autora destaca, ainda, que o Brasil possui um abundante aparato regulatório - Leis de Uso e Ocupação do Solo, Parcelamento do Solo Urbano, códigos de edificação -, que normatiza a produção do seu espaço urbano, não sendo, portanto, a falta de planos e leis a causa do crescimento das cidades de modo predatório; afırma também que a legislação urbanística de regulação do espaço urbano implica padrões de produção do ambiente construído urbano (MARICATO, 2002).

Neste contexto, de acordo com Sanchez (1999), o city marketing e os planos estratégicos, os quais configuram-se como os principais instrumentos do novo planejamento urbano, vêm se transformando em função básica do poder local nos últimos anos, tornando-se uma verdadeira "fábrica de imagem", que tem como objetivo final "vender a cidade". 0 autor complementa ainda que este novo modelo de gestão da cidade tem alterado fortemente a atuação do poder local em relação às suas prioridades de investimentos e promoção de políticas públicas, tendo em vista que, com frequência, programas e projetos de cunho social são deixados de lado em prol de interesses privados, cujos atores passam a exercer papel dominante nos processos decisórios das políticas urbanas (SANCHEZ, 1999).

\section{Os seus sonhos não podem esperar}


Diante do exposto, o presente artigo teve como intuito principal compreender de que modo todos esses fatores têm sido abordados no planejamento urbano da cidade de Campos dos Goytacazes/RJ, e se ele tem considerado tais aspectos. Para tanto, foi realizado um levantamento da legislação urbana municipal vigente, visando identificar e analisar os pontos que se referem às praças públicas. Entre as leis averiguadas, estão 0 Plano Diretor de 2008, o qual está passando por revisão, e as Leis de Uso e Ocupação do Solo Urbano (Lei n 7.974, de 10 de dezembro de 2007) e de Parcelamento do Solo (Lei n 7.975, de 12 de dezembro de 2007), as quais são complementares ao Plano Diretor de 2008 no que tange à regulação dos espaços públicos urbanos da cidade.

Além disso, foi realizado um levantamento das notícias veiculadas pelo site da prefeitura, entre 2010 e 2019, que abordavam as referidas questões. Tal recorte foi adotado com o objetivo de averiguar como esses espaços livres públicos foram tratados pelo governo vigente entre 2008 e 2016, do qual esteve à frente a então prefeita Rosinha Garotinho, e pelo governo atual, assumido pelo prefeito Rafael Diniz em 2017. Vale destacar que, embora o mandato de Rosinha Garotinho tenha se iniciado em 2008, o registro de notícias disponível no site vai apenas até 2010, o que determinou o limite desta pesquisa. Ressalta-se ainda que, devido ao recorte locacional adotado, serão abordadas apenas as praças localizadas na cidade de Campos dos Goytacazes, excluindo-se distritos e localidades.

É importante destacar que o município de Campos dos Goytacazes, que, junto a outros, compõe a denominada Região Norte Fluminense, localizada no interior do estado do Rio de Janeiro, assim como Macaé e, mais recentemente, como São João da Barra, destaca-se economicamente na região, devido às atividades ligadas ao petróleo e às instalações portuárias. Por um tempo, a economia da região foi baseada no cultivo da cana-de-açúcar, que entrou em decadência entre as décadas de 1970 e 1980, acarretando o declínio dessa economia. Contudo, com a descoberta do petróleo na bacia de Campos, na década de 1970, os recursos municipais tiveram aumento significativo por meio do recebimento dos royalties.

A referida mudança econômica trouxe rápidas e significativas transformações para a cidade de Campos dos Goytacazes sob os mais variados aspectos, refletindo-se ainda na sua paisagem e estrutura urbana como um todo. Nesse contexto, acredita-se que o processo de urbanização vivenciado pela cidade, mais especificamente desde o "boom" do petróleo, foi estruturado sem relacionar a expansão do tecido urbano com o conjunto de espaços livres públicos, com a infraestrutura urbana, nem com as demandas cotidianas da população. Os interesses diversos dos atores sociais envolvidos no processo de urbanização direcionaram o crescimento e a consolidação da forma urbana da cidade de Campos configurando e amplificando problemas urbanos já existentes (ALIPRANDI, 2017).

Diante desse cenário, analisar o modo como as praças vêm sendo tratadas pelo planejamento no município torna-se imprescindível para compreender seu papel atual na esfera pública e no tocante às interações sociais e expressão da cidadania. Além disso, tal estudo poderia vir a contribuir na elaboração de políticas públicas que visem à qualificação estes espaços livres públicos e outros existentes na cidade.

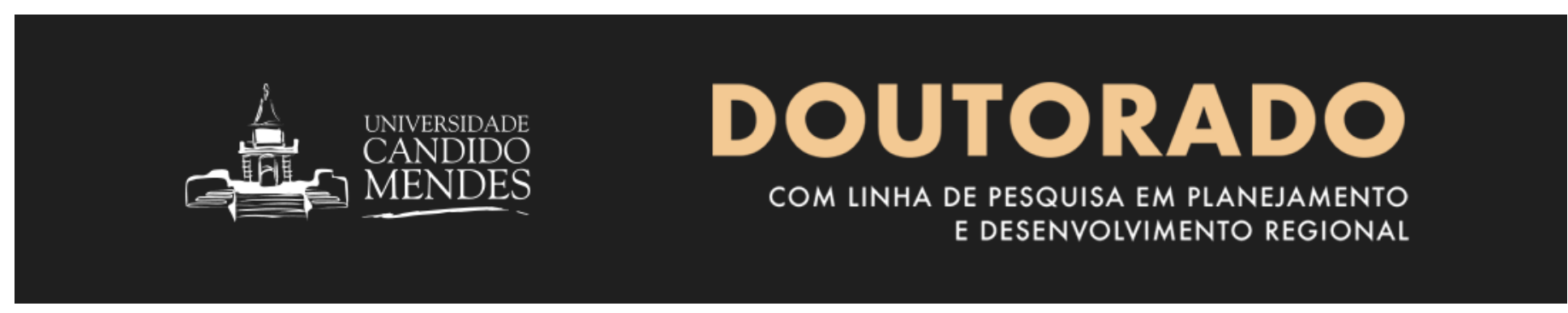




\section{Metodologia}

Como percurso metodológico, foram realizadas, inicialmente, pesquisas bibliográficas, as quais contribuíram para o aprofundamento teórico, conceitual e técnico, que serviu como base para o artigo. Para tanto, foram realizadas consultas em dissertações, teses, outros artigos e livros, com o intuito de alcançar a compreensão de temáticas pertinentes. Posteriormente, procedeu-se à pesquisa documental, a partir da qual visou-se identificar informações gerais e dados históricos relevantes em relação ao município, a configuração das praças públicas em sua paisagem, bem como compreender de que modo tais espaços livres públicos têm sido tratados pelo planejamento urbano municipal. Para possibilitar tal compreensão, sucedeu-se uma análise da legislação vigente no município, e, além disso, levantaram-se reportagens oficiais do site da prefeitura publicadas no período de 2010 a 2018, traçando-se assim um panorama geral de como os últimos governos vêm portando-se no que diz respeito às praças na cidade de Campos dos Goytacazes. Dessa forma, a pesquisa documental permitiu contextualizar a análise proposta no cenário local, constatando suas especificidades e contradições.

\section{As praças públicas na paisagem urbana do município de Campos dos Goytacazes}

Enquanto componentes da paisagem urbana, as praças, ao longo de sua existência, passam por transformações físicas e simbólicas, que acompanham e refletem cada momento da evolução histórica de uma cidade e sua sociedade. Embora tais mudanças denotem uma intrínseca relação entre as pessoas e o seu entorno, isso não significa que todos os indivíduos sejam representados e beneficiados de maneira igualitária. Ao contrário disso, o sistema capitalista por vezes manifesta-se de forma perversa, excludente e desigual, promovendo, entre outras sequelas, acesso diferenciado ao urbano e à vida em sociedade.

De acordo com o que foi apresentado na introdução deste artigo, o município de Campos dos Goytacazes passou, nas últimas décadas, por grandes transformações econômicas, as quais repercutiram na sociedade e na sua paisagem urbana. Desse modo, buscou-se analisar brevemente a forma como as praças públicas inserem-se na paisagem urbana de Campos, considerando suas características morfológicas principais e tendo em vista a forma como todos os fenômenos por ela vivenciados interferiram e/ou têm interferido na produção da cidade.

Conforme apurado por meio de pesquisas bibliográficas, considerando-se as primeiras onze praças construídas em Campos dos Goytacazes, a maior parte delas concentrava-se no atual centro histórico da cidade, onde teve início a formação do núcleo urbano (SANT'ANNA, 2017). Destaca-se ainda que, apenas uma - a Santo Antônio - localizava-se em Guarus e, ainda assim, em um bairro cuja localização também é extremamente próxima do centro histórico. Tal desprivilégio se estende aos dias atuais, quando a margem norte do rio Paraíba do Sul permanece possuindo um número significativamente mais reduzido desta tipologia de espaços livres públicos do que a margem sul.

Atualmente, apesar do maior número de praças e da sua distribuição de forma mais heterogênea nos bairros da cidade, a área central continua privilegiada em termos de quantidade e infraestrutura. Constatou-se que das oitenta e quatro praças públicas identificadas no município, quinze localizam-se no centro da cidade, sendo este um número bastante significativo, levando-se em consideração que a maioria dos bairros possuem apenas uma praça.

Analisando tal panorama em conjunto com as informações ilustradas pela Figura 1, pode-se admitir que, à medida que o perímetro urbano foi se expandindo, e junto a ele a população, as praças foram sendo construídas de forma mais pulverizada ao longo do tecido urbano do município na tentativa de contemplar a crescente demanda por espaços livres públicos de lazer. No entanto, percebe-se de maneira clara que tal pulverização ocorre de forma heterogênea, porém, ainda desigual, ao passo que, destas oitenta e quatro praças, apenas vinte e cinco estão localizadas na margem norte do rio Paraíba do Sul. 
A partir das informações levantadas, nota-se que há, atualmente, em Campos dos Goytacazes, uma quantidade significativa de praças; no entanto, tal panorama sugere algumas reflexões. Por um lado, pode-se considerar que se trata de uma situação interessante, tendo em vista que, dessa forma, um maior quantitativo de pessoas pode dispor dessa tipologia de espaço livre público relativamente próximo de sua residência, cabendo, no entanto, destacar a existência de bairros do município que não são contemplados com praças, como se nota nos vazios do mapa da Figura 1.

Figura 1: Mapa indicando a localização das praças existentes atualmente na cidade de Campos dos Goytacazes/RJ.
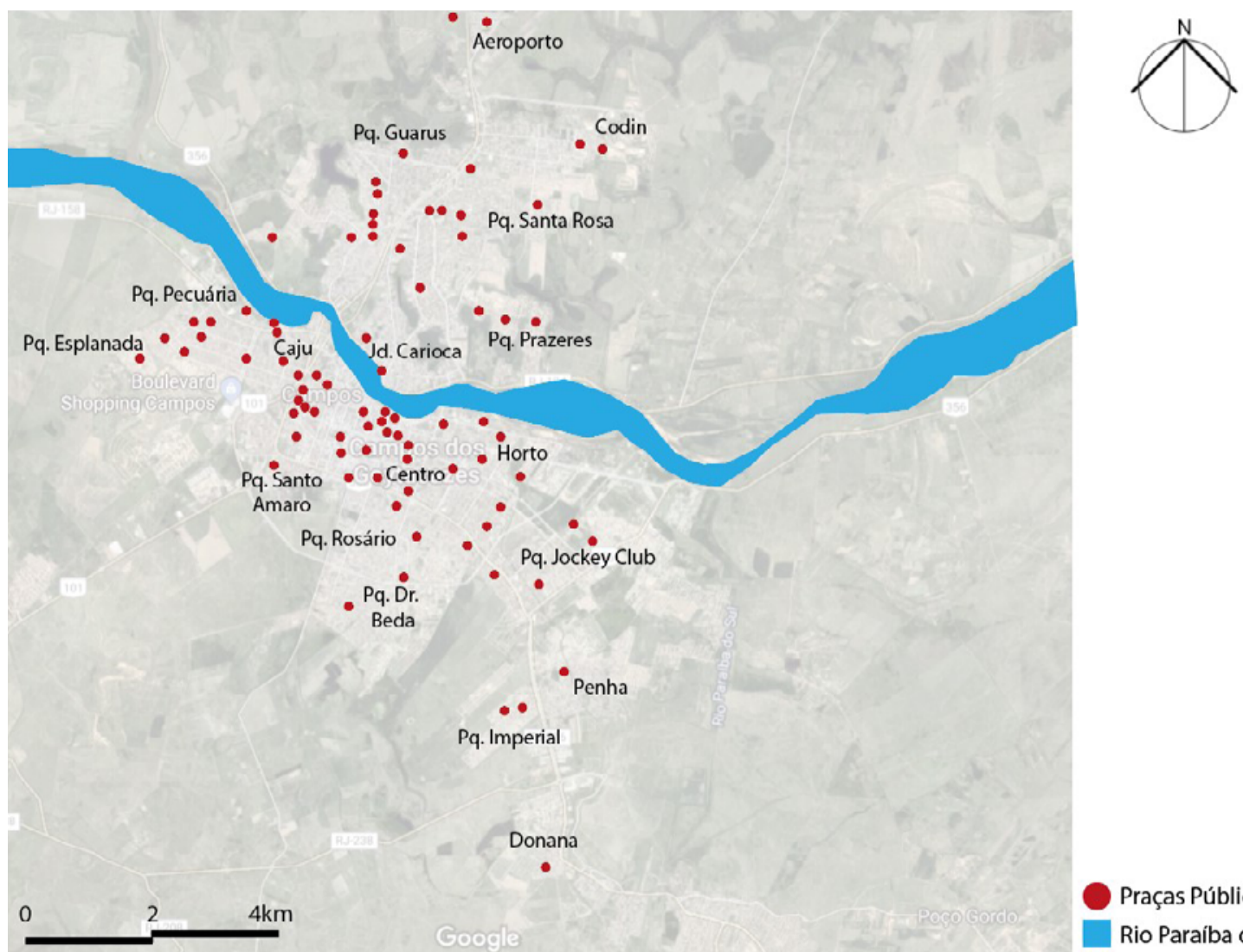

Fonte: organizado pela autora sobre imagem do Google Maps, 2019. 
Por outro lado, há que se considerar que estes espaços demandam manutenção constante para garantir a preservação de sua estrutura e boas condições de uso, 0 que implica em custos para a máquina pública e, consequentemente, um desafio para o planejamento, tendo em vista a grande demanda existente. Desse modo, na prática, o que se observa é que muitas dessas praças acabam apresentando uma estrutura precária ou manutenção deficiente, prejudicando, em algum grau, o seu uso. É importante mencionar que não basta que o poder público construa e entregue praças à população, mas que continue incluindo estas em suas pautas, tendo em vista a importância que representam para a cidade. Outro aspecto sobre o qual é válido refletir é o fato de que a existência de praças em todos os bairros e a falta de atratividade para uso das que estão em bairros distintos do que se reside pode influenciar na menor interação entre usuários provenientes de contextos diversos, empobrecendo as trocas e gerando uma situação na qual cada grupo se isola em sua ilha. Sob este ponto de vista, torna-se imprescindível garantir a boa acessibilidade e conectividade da malha urbana e evitar a homogeneização dos espaços livres públicos, de modo que estes se tornem atrativos e complementares, compondo de fato um sistema.

Conforme observou-se, as maiores densidades demográficas estão localizadas em áreas periféricas da cidade e, quando sobrepõem-se tais informações com as da Figura 1 - a qual destaca a localização das praças -, é possível perceber nitidamente o grande quantitativo populacional que não é contemplado com tal tipologia de espaços livres públicos próximos de sua residência ou, ainda, a desproporção entre estes e o volume de pessoas a ser atendido, em função da inexistência de quantidade adequada de praças, o que denota a necessidade de um planejamento mais eficiente que leve em conta tais especificidades.
Em virtude do exposto, percebe-se que concentrações populacionais consideráveis se veem deficientes de espaços livres públicos, especialmente praças, tendo em vista que, na maioria das vezes, o surgimento de novos bairros e loteamentos não é acompanhado por infraestrutura adequada, fazendo com que seus moradores tenham que se deslocar para outras áreas da cidade em busca, por exemplo, de espaços de lazer e serviços como escolas e hospitais.

Tendo em vista o papel dos espaços públicos enquanto instrumentos de valorização fundiária, tal cenário representa uma valorização diferenciada do solo urbano, a qual acaba por submeter o acesso à cidade ao mercado. Neste sentido, percebeu-se que as áreas com os maiores valores de solo são também as que possuem o maior número de praças e as que possuem melhor infraestrutura. Tais áreas contemplam grande parte do comércio e da prestação de serviços da cidade, bem como das edificações residenciais de alto padrão e da boa infraestrutura urbana. Em contrapartida, à medida que se caminha para os bairros mais periféricos da cidade, nos quais estão também os menores valores do solo, as praças vão ficando mais escassas e em condições de uso menos adequadas. Tais áreas, por sua vez, caracterizam-se por um perfil preponderantemente residencial de baixo padrão, manifestando-se, em menor quantidade, a presença de comércios e prestação de serviços.

Situação semelhante se nota ao considerar a renda média por domicílio em Campos dos Goytacazes, constatando-se que as menores rendas por domicílio também encontram-se nas áreas periféricas da cidade, reforçando a percepção de que a população mais pobre é pior atendida em relação à disponibilidade de espaços livres públicos de permanência. Tal observa-

\section{Os seus sonhos}

não podem esperar 
ção traduz a face cruel do capitalismo que, ao transformar o espaço em mercadoria, mantém uma parcela da população à margem do desenvolvimento e sujeita aos interesses do mercado, excluindo-a da vida social urbana e gerando segregação socioespacial.

Como é possível constatar, certas áreas da cidade acabam por não receber investimentos de forma adequada, acentuando seu processo de desvalorização e cerceando os indivíduos de locais de lazer, serviços básicos e infraestrutura urbana apropriada. Percebe-se, assim, que a paisagem urbana é claramente segregada e vinculada à transformação, por parte do sistema capitalista, dos cidadãos em consumidores.

Outro aspecto observado em relação às praças na paisagem urbana de Campos é a existência de uma certa homogeneização dos espaços, principalmente nas praças localizadas nos bairros de classe média baixa e parte significativa das situadas nos bairros de classe média. A impressão que se tem é a de que o poder público tem adotado quase que uma fórmula na hora de construir ou reformar as praças, o que contribui para tornar o processo mais rápido, como uma produção em série. Além disso, pode-se supor que, dessa forma, acredita-se que a população se sentiria contemplada de uma forma mais igualitária ao perceber que a praça do seu bairro possui os mesmos equipamentos que a de outros. 0 fato é que tal prática acaba trazendo certo prejuízo à diversidade da paisagem no que tange às praças, o que pode vir a interferir, inclusive, no interesse gerado ou não por parte da população.

Desse modo, a espacialização das informações aqui apresentadas permite afirmar que as praças com meIhores condições e possibilidades de uso, em geral, estão localizadas nas áreas de maior valor de solo, maior renda por domicílio e média densidade demográfica, demonstrando a apropriação do mercado imobiliário destes espaços. Conforme mencionado anteriormente, as praças de Campos dos Goytacazes encontram-se distribuídas de modo heterogêneo pela malha urbana, porém, em áreas cuja população possui menor renda, nota-se a existência de certas características que demonstram um certo desprivilégio em relação a outras áreas da cidade. Ressalta-se ainda, como já informado, a existência de bairros onde praças não são encontradas e a existência de regiões bastante populosas com um quantitativo de praças insuficiente para atender a todos.

Destaca-se ainda que, tendo em vista que uma das funções das praças na morfologia urbana é o embe- lezamento da paisagem, o mercado imobiliário acaba, muitas vezes, tirando partido dessa característica para vender maior qualidade de vida à população mais rica. Tal aspecto fica claro ao analisar e notar diferenças entre as praças localizadas em bairros de classe média baixa, média e média alta. Fica clara, assim, a existência de um "jogo de interesses" entre o capital, o estado e os indivíduos, o qual enfatiza o caráter segregador e desigual da cidade contemporânea.

\section{Breve apanhado da legislação urbana municipal}

A história de Campos dos Goytacazes foi marcada por uma série de planos urbanísticos realizados em diferentes contextos e com objetivos diversos. Entre propostas de melhoramentos sanitários, tentativas de ordenamento do processo de expansão urbana, esforços de promoção do desenvolvimento físico e territorial urbano do município, muitas foram as mudanças sofridas pela cidade. Segundo Sant'Anna (2017):

No século $X X$, as leis gerais que trataram a respeito da organização do espaço urbano em Campos dos Goytacazes foram: o Plano de Saturnino de Brito de 1902, o Plano Urbanístico de 1944, o Plano de Desenvolvimento Urbanístico e Territorial de Campos de 1979, a Lei Orgânica Municipal de 1990 (e sua posterior atualização em 2014), o Plano Diretor Municipal de 1991 e, no século XXI, o Plano Diretor de 2008, que está em vigência (SANT'ANNA, 2017).

Contudo, conforme afirma Faria (2005), embora todos esses planos urbanísticos tenham sido elaborados, sua implementação não ocorreu de maneira integral. Além disso, destacou-se a ausência de intervenções concretas nas áreas periféricas, voltadas para as necessidades das camadas populares, impedindo que se eliminassem as contradições do espaço urbano e a oposição centro $x$ periferia, as quais manifestam-se como grandes problemas para o município. (FARIA, 2005)

No que diz respeito aos espaços livres públicos, atualmente, o ainda vigente Plano Diretor de 2008 do município de Campos dos Goytacazes trata das praças basicamente em três momentos: no Capítulo II, que versa sobre a cidadania e inclusão social; no 
Capítulo V, o qual aborda o desenvolvimento urbano e a qualidade ambiental; e no Capítulo II do Título V, que dispõe sobre os instrumentos de intervenção urbana (CAMPOS DOS GOYTACAZES, 2007).

No que diz respeito ao Capítulo II, no inciso IV do artigo 39 (Seção IV), tem-se que "Elaborar e implantar projetos para requalificação de praças e espaços públicos para promoção de atividades esportivas e de lazer, melhorando sua acessibilidade" (CAMPOS DOS GOYTACAZES, 2007) deveria estar entre as ações e medidas prioritárias de planejamento para o esporte e lazer do município. No inciso II do artigo 40 (Seção IV), por sua vez, consta que "Promover atividades esportivas nos espaços públicos, parques e praças, de cada bairro ou distrito" (CAMPOS DOS GOYTACAZES, 2007) deveria ser uma das ações e medidas prioritárias de gerenciamento para o esporte e lazer do município. Desse modo, prevê a necessidade de requalificação dos espaços públicos e sugere estes como aliados na valorização e promoção da cultura e dos esportes, destacando, para tanto, a importância de melhorar a acessibilidade a estes espaços.

Já no que tange ao Capítulo V, o inciso I do artigo 89 (Seção II) estabelece que "Revitalizar espaços culturais - como o Centro Histórico, o Horto, os casarões e usinas, parques, jardins e praças - potencializando seus usos, para o desenvolvimento de projetos culturais e áreas de lazer" (CAMPOS DOS GOYTACAZES, 2007) deve ser considerado como ação e medida de gerenciamento a ser adotada para a valorização do patrimônio natural e cultural.

Ainda no referido capítulo, o inciso II do artigo 91 (Seção III) dispõe a respeito das estratégias de qualificação dos espaços públicos e privados e de melhoria dos serviços urbanos prestados à população, que se adote enquanto diretriz:

A implementação de equipamentos turísticos, culturais e de lazer, em parques, praças e áreas verdes, associada à melhoria de facilidades urbanas e ao estímulo à instalação de atividades que conciliem a utilização pública e a preservação ambiental, segundo os princípios de sustentabilidade (CAMPOS DOS GOYTACAZES, 2007).
Por fim, no Capítulo II do Título V, o inciso II do artigo 223 (Seção I - Subseção II) estabelece que os "Equipamentos públicos dotados de áreas verdes, como parques, praças, bosques e hortos existentes ou a serem criados" (CAMPOS DOS GOYTACAZES, 2007) estão inclusos entre as áreas de especial interesse de recuperação e valorização paisagística.

Diante disso, o Plano Diretor destaca as praças como uma das tipologias de espaços públicos importantes para a promoção de atividades culturais, esportivas e turísticas, valorizando também o patrimônio cultural e natural. Além disso, o Plano aponta a necessidade de "Inventariar e selecionar espaços públicos ociosos para promoção de atividades culturais permanentes" (CAMPOS DOS GOYTACAZES, Capítulo II, Seção II, artigo 31, inciso II, 2007).

A Lei de Uso e Ocupação do Solo Urbano de Campos dos Goytacazes (Lei n 7.974, de 10 de dezembro de 2007), a qual complementa o Plano Diretor de 2008, não apresenta diretrizes que tratem das praças e dos demais espaços públicos do município, mencionando o termo "praça" apenas para vedar a instalação de estações e torres de radiocomunicação dos serviços de telecomunicações nesses espaços. Para além disso, tendo em vista que a lei considera que equipamentos comunitários "são os equipamentos públicos de educação, cultura, segurança, assistência social, saúde, esporte, recreação e lazer, administração e similares", o artigo 107 afirma que, quando um imóvel urbano, privado ou público for considerado necessário para fins de implantação de equipamentos urbanos e comunitários, seu proprietário poderá exercer em outro local, ou alienar, mediante escritura pública, o direito de construir. Este aspecto demonstra que certa relevância foi conferida aos espaços públicos para desempenhar suas funções, alterando a configuração espacial urbana (CAMPOS DOS GOYTACAZES, 2007).

A Lei de Parcelamento do Solo do município de Campos dos Goytacazes (Lei n ${ }^{0} 7.975$, de 12 de dezembro de 2007), por sua vez, trata das praças basicamente em dois momentos: no capítulo I, que versa sobre os requisitos urbanísticos e ambientais; e no capítulo II, o qual trata do processo administrativo (CAMPOS DOS GOYTACAZES, 2007).

No capítulo I, o inciso III do artigo 22 (Seção II - Subseção II) dispõe que as áreas públicas destinam-se à implantação de redes de infraestrutura, de equipamentos urbanos e comunitários e áreas verdes, entre 
as quais estão discriminadas as praças (CAMPOS DOS GOYTACAZES, 2007).

Já no capítulo II, o inciso VII do artigo 131 (Seção V Subseção I) estabelece que, para que um projeto de parcelamento seja aprovado nas modalidades de loteamento e desmembramento, é necessário que seja aprovado um cronograma para implantação e implementação das obras e serviços contendo, no mínimo:

0 número total de lotes e quadras, área total da gleba, áreas destinadas para implantação de equipamentos urbanos e comunitários, áreas destinadas a áreas verdes e praças, área útil do loteamento, área destinada ao arruamento, outras áreas com restrições, se existirem, e respectivos percentuais (CAMPOS DOS GOYTACAZES, 2007).

No referido capítulo, o inciso $\|$ do artigo dispõe ainda que o projeto de loteamento e de condomínio urbanístico deve vir acompanhado de projeto de arborização de ruas, praças e áreas verdes projetadas, sendo um dos critérios a serem adotados o de que "As praças deverão ter, pelo menos, metade de sua área total arborizada" (CAMPOS DOS GOYTACAZES, 2007). Desse modo, nota-se na legislação a preocupação das praças públicas tornarem-se espaços para a implantação de áreas verdes.

Além do exposto, a Lei de Parcelamento e Uso de Solo de Campos dos Goytacazes também define, em seu artigo 27, que a soma total das áreas destinadas ao uso público nos loteamentos não pode ser inferior a $35 \%$ da área total da gleba e, ainda no mesmo artigo, o parágrafo único destina 15\% das áreas ao uso público, excluindo o sistema viário e as faixas de domínio. No artigo 37, por sua vez, fica definido que os espaços designados para as áreas verdes devem ser de, pelo menos, $6 \%$ da gleba (CAMPOS DOS GOYTACAZES, 2007).

Assim, nota-se que a Lei $n^{0}$ 7.975, de 12 de dezembro de 2007 versa, basicamente, sobre a garantia de reserva de uma determinada porcentagem da área par- celada para áreas públicas destinadas, entre outras, à construção de praças. Ademais, demonstra certa atenção em relação à importância das áreas verdes ao exigir a arborização de, pelo menos, metade da área das praças públicas.

Diante da análise realizada em relação à legislação municipal vigente no tocante às praças de Campos dos Goytacazes, observa-se ainda uma certa timidez ao tratar do tema, levando-se em consideração a importância de tais espaços livres públicos para 0 município e as poucas diretrizes traçadas sobre estes. Embora tenham sido destacadas medidas interessantes, há que se ponderar também que a precária fiscalização torna-se um obstáculo à sua correta implementação.

\section{Ações protagonizadas pela prefei- tura entre 2010 e 2019}

Após a análise das informações levantadas em notícias do site da Prefeitura de Campos dos Goytacazes, percebeu-se a existência de algumas diferenças na forma como os governos Rosinha Garotinho (20082016) e Rafael Diniz (2017-atual) tratam das questões relacionadas às praças da cidade, não obstante ambos as insiram de alguma forma em suas pautas.

Contudo, antes de apresentar os dados levantados, é imprescindível ressaltar que cada um dos governos acima destacados se deram em contextos diferentes e, principalmente no que diz respeito a questões econômicas, o período no qual Rosinha Garotinho foi prefeita foi de maior abundância para o município, o que pode ter contribuído para que o panorama a seguir exposto tenha se delineado. 0 gráfico (Figura 8) abaixo reforça tal dicotomia entre os períodos governados por Rosinha Garotinho e Rafael Diniz ao apresentar os valores de Royalties + Participações Especiais recebidos pelo município de Campos dos Goytacazes entre 2008 e 2019.

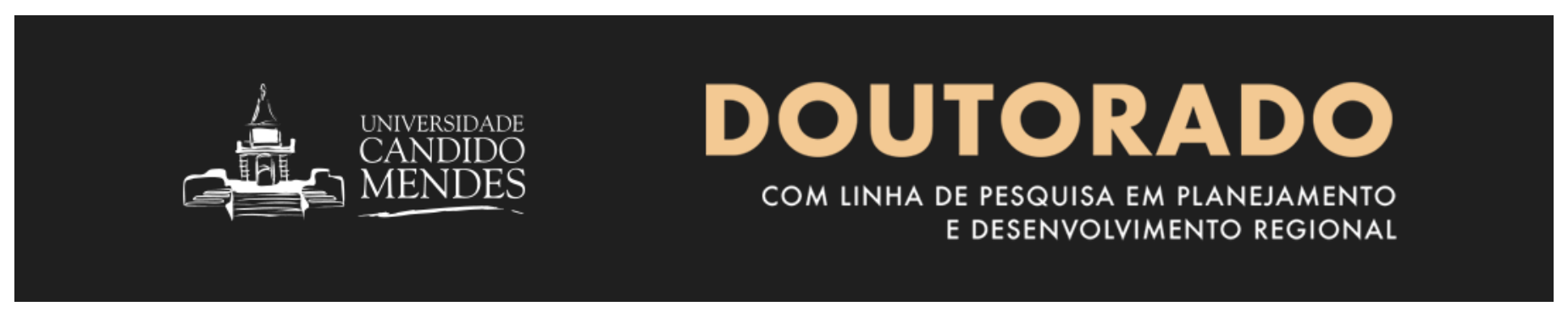




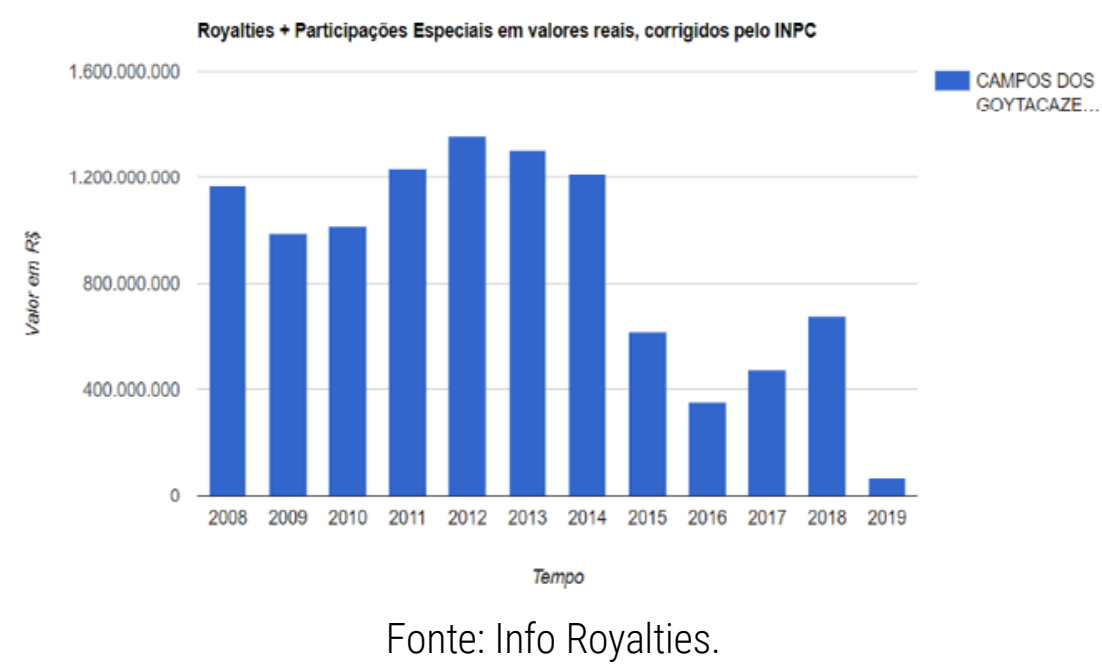

Diante do exposto, no governo Rosinha Garotinho, constatou-se que um grande número de praças foi reformado ou construído pela própria prefeitura em diferentes bairros de Campos dos Goytacazes. De um modo geral, as obras contemplavam reforma ou implantação de quadras poliesportivas e instalação de coberturas nelas; colocação de nova iluminação visando maior segurança e incentivo ao uso noturno dos espaços; reparo de playgrounds; realização de melhorias na pavimentação e mobiliário em geral; remodelação do paisagismo; inserção ou conserto de equipamentos para prática de exercícios físicos; adaptações no intuito de promover condições de acessibilidade; reforma de quiosques e banheiros públicos.

Segundo reportagem de 2010, publicada no site da Prefeitura de Campos dos Goytacazes, dez novas praças estavam, à época, sendo construídas no município e outras dez sendo reformadas, com o objetivo de ofertar espaços de lazer aos moradores. Neste contexto, foram mencionadas as praças da Comunidade Tira Gosto, do Parque Prazeres, do Parque Esplanada, de Custodópolis, Lebret I e II, praça ao lado da escola Maria Lucia, Parque Alberto Sampaio, Almirante Tamandaré, Luiz Gualda Júnior, IPS e Praça do Tamarindo. Ainda conforme noticiado, o então coordenador de infraestrutura destacava que a Secretaria de Obras e Urbanismo vinha realizando um levantamento de todas as praças do município para que fossem realizadas as reformas necessárias em cada uma delas (FARIA, 2010).

Destaca-se que, entre as doze praças e/ou bairros acima mencionados, quatro ficam localizadas na margem norte do Rio Paraíba do Sul (Guarus) e as outras oito, na margem sul. Além disso, observa-se que a grande maioria delas está situada em bairros de classe média e média baixa de Campos dos Goytacazes. Conforme será visto adiante, esta é uma característica que se destaca nas obras do governo Rosinha Garotinho, embora haja considerável heterogeneidade em relação aos bairros cujas praças foram contempladas.

Em 2011, encontraram-se, nas reportagens levantadas, referências à Política de Recuperação do Patrimônio Público e ao Programa Brilha Campos. No que diz respeito à Política de Recuperação do Patrimônio Público, não foram encontradas informações complementares que possibilitassem uma melhor compreensão, tendo ela sido citada no contexto de relato de reforma por parte da prefeitura na Praça São Cristóvão, localizada no bairro Jardim Carioca. A reportagem a mencionava como mais uma das reformas que fazia parte do programa, dando a entender que outras também já haviam sido feitas.

O Programa Brilha Campos, por sua vez, foi realizado pela Campos Luz ${ }^{1}$ e, segundo relatado, visava a iluminação de praças que estavam sendo reformadas e construídas pela prefeitura, com o objetivo principal de melhorar a qualidade de vida da comunidade,

1 Companhia municipal de iluminação pública de Campos dos Goytacazes. 
proporcionando segurança, lazer e conforto aos moradores. Na data da reportagem, dezessete praças já haviam recebido nova iluminação, entre as quais estavam as do Parque Lebret; do bairro Caju; da Penha; da comunidade Tamarindo; Praça $1^{\circ}$ de Maio; Praça Esperanto; entre outras (THEDERICH, 2011).

Cabe ressaltar, que algumas citadas em notícias de 2010 só tiveram suas obras concluídas em 2011, como a Praça Ovídio Ferreira, no Parque Lebret; a Praça do Tamarindo, no Centro; a Praça do Parque Prazeres, em Guarus; e a Praça da Tira Gosto. Também foram mencionadas obras na Praça da Penha e na Praça do Saco (Dr. Ribeiro do Rosário), no parque Leopoldina; em Donana; no Parque Santo Antônio; Caju e na Praça Esperanto.

Já em 2012, as notícias levantadas no site da Prefeitura de Campos dos Goytacazes versam sobre a reforma das praças José Dias Nogueira, no Parque Custodópolis; de Nova Brasília; e do IPS (ASSIS, 2012). Aparentemente, um número menor de praças teria sido reformado ou construído nesse ano; contudo, observa-se ainda a existência de ações nesse sentido.

0 ano de 2013, por outro lado, demonstrou uma atividade bastante intensa da prefeitura em relação às obras de praças em Campos dos Goytacazes, entre as quais foram mencionadas a Praça Prudente de Morais (Chá Chá Chá), localizada no centro histórico da cidade; a Praça do Santa Rosa, localizada no Parque Santa Rosa; a Praça Otacílio Lisboa, no Parque Tarcísio Miranda; a Praça do Amarelinho, no Parque Nogueira, em Guarus; a praça do Horto; a praça da Lapa; as Praças Planejada e do Cacique, ambas localizadas na Avenida Nazário Pereira Gomes; a Praça Almirante Tamandaré, localizada na Avenida Pelinca, entre as ruas Marcílio Dias e Almirante Greenhalgh; a Praça Nilo Peçanha, no Jardim São Benedito; e a praça do Parque Santo Amaro.
Vale ressaltar que a reforma das Praças Prudente de Morais e do Amarelinho estiveram envolvidas em contextos mais amplos dentro das ações do governo. A Praça Prudente de Morais fez parte do projeto da prefeitura de revitalização do centro histórico da cidade, o qual contemplou outras obras como, por exemplo, a de infraestrutura. Já a reforma da Praça do Amarelinho fez parte do projeto de revitalização da Avenida José Carlos Pereira Pinto, que se tornou um corredor de passagem para os distritos de Travessão, Conselheiro Josino e para o município de São Francisco de Itabapoana.

Além disso, em 2013 a prefeitura também desenvolveu um amplo projeto de paisagismo, que contemplou praças e canteiros espalhados pelo município. As praças já reformadas também vêm passando por constante manutenção, seguindo um cronograma estabelecido pela secretaria. Entre as que foram contempladas, estão: Praça Nilo Peçanha (Jardim São Benedito), Praça do Flamboyant, Praça do Tamarindo, Praça do Almirante, entre outras.

De acordo com uma reportagem de 2013 do site da prefeitura, nos bairros e distritos, mais de cinquenta praças haviam sido construídas e/ou reformadas nos últimos quatro anos, entre elas, Praça João XXIII, no Parque Nova Brasília; Praça da Penha; Praça de Donana; Praça de São Benedito, em Goitacazes; Praça São Cristóvão, no Jardim Carioca; Praça da Tira Gosto, no bairro da Lapa; Praça do Parque Aldeia; Praça Almirante Tamandaré, na Pelinca; Praça de Ururaí; entre outras (FILHO, 2013).

Uma reportagem de julho de 2013 afirma que a então prefeita Rosinha Garotinho havia criado a Comissão de Praças e Jardins, a qual englobaria nove secretarias, sendo que cada uma, com seu trabalho específico, ficaria responsável por resolver a problemática 
das praças e jardins dentro de sua área. De acordo com o então subsecretário de Limpeza Pública, Praças e Jardins, Carlos Morales, em menos de dois meses, os órgãos responsáveis já haviam conseguido resolver vários problemas, como o da Praça da República, onde toda a iluminação foi trocada; o das Praças do Parque Flamboyant I e II, onde os brinquedos quebrados foram trocados por novos, entre outras intervenções (MARIA, 2013).

A reportagem afirmava ainda que, apesar do grande número de praças existentes no município, a prioridade da Comissão seria a de cuidar daquelas consideradas como principais (por serem maiores), as quais totalizavam quarenta e uma praça, e eram classificadas como A. Entre elas, estavam o Jardim São Benedito, a Praça São Salvador, a Praça de Nova Brasília. As demais, classificadas como B, C, D e E, possuíam menor extensão, mas também teriam seus problemas resolvidos posteriormente (MARIA, 2013).

Segundo informações noticiadas no site da Prefeitura de Campos dos Goytacazes, em 2014, a então prefeita inaugurou a reforma da praça do Parque Alvorada; da nova praça do Parque Aldeia; da Praça dos Ciganos, no Parque Nova Brasília; da Praça Santa Helena, Iocalizada na Matinha, no parque Jóquei Clube. Todas foram relacionadas como parte da programação de aniversário de 179 anos da cidade (ABREU, 2014).

Em 2015, foram inauguradas as Praças Maria Geysa Messias Genásio, construída no Condomínio Recanto Solares Campistas; Morar Feliz² ${ }^{2}$ do Parque Esplanada (FILHO, 2015); e outra no Recanto dos Campeões, do Morar Feliz Tapera II. A construção da praça é fruto da realização do projeto Viver Feliz, que levou ações de cidadania para as famílias que foram contempladas com casas do Programa Morar Feliz, construídas com recursos da Prefeitura de Campos dos Goytacazes (FILHO, 2015).

2 Programa habitacional financiado pela prefeitura municipal durante o governo da prefeita Rosinha Garotinho com o intuito de construir conjuntos habitacionais voltados para a população vulnerável residente em áreas consideradas de risco.
Em 2016, último ano do governo da então prefeita, Rosinha Garotinho, foram encontradas notícias com alusão a obras de três praças em Campos dos Goytacazes, todas as três localizadas em Guarus: a praça do Parque Rio Branco, a Praça Sérgio Luiz Paes da Silva (Lilico), ao lado da Igreja Nossa Senhora da Conceição, e a Praça do Povo.

Já em relação ao governo Rafael Diniz, uma reportagem de 2017 da Prefeitura de Campos dos Goytacazes relata o compromisso do prefeito de "[...] massificar o esporte em todo o município, como principal proposta de melhorar a qualidade de vida dos campistas". Neste contexto, é mencionada a entrega à população da academia da Praça Santo Antônio, no Jardim Santo Antônio, por parte da Fundação Municipal de Esportes (FME), destacando que esta, com o apoio da iniciativa privada, estaria trabalhando também na reforma das academias das praças do Parque Imperial e do Jardim São Benedito.

Além desta atividade realizada com o apoio da iniciativa privada, também foi sancionado pelo prefeito, em 2017, o programa "Adote uma Praça", previsto na Lei no 8771/17. Tal programa prevê parceria entre o município, a iniciativa privada e a sociedade civil interessados em assumir o compromisso de realizar a manutenção e a conservação de logradouros públicos em todo o município, entre os quais estão consideradas as praças (CAMPOS DOS GOYTACAZES, 2017). Com a finalidade de melhorar a urbanização da cidade, a Prefeitura de Campos dos Goytacazes regulamentou o programa "Adote uma Praça" por meio da Secretaria Municipal de Desenvolvimento Ambiental (SMDA).

Segundo a Lei n 8771/17, a adoção de um logradouro público poderá ser destinada para urbanização; implantação de áreas de esporte e lazer; conservação e manutenção da área adotada; realização de atividades culturais, esportivas ou de lazer; e medidas de proteção e segurança.

Em 2017, a Praça $1^{0}$ de Maio (inaugurada em 2010 pelo então prefeito Nelson Nahin) inaugurou o programa, tendo sido adotada por membros da Câmara Junior Internacional. Até o presente momento, de acordo com os registros encontrados em notícias locais, 
esta foi a única praça da cidade a ser adotada.

Também em 2017, após solicitação da comunidade do Parque Prazeres para que a praça do bairro fosse revitalizada, a SMDA, por meio do Setor de Arborização, realizou um mutirão junto aos moradores para a realização de uma intervenção no local, mais uma vez demonstrando um exemplo de iniciativa desenvolvida com apoio da sociedade.

Em 2018, foram realizadas pela prefeitura obras de revitalização do Jardim São Benedito, que contemplaram a reforma e a pintura das grades do entorno da praça, obras nas quadras, brinquedos infantis, nova iluminação, entre outros aspectos. A entrega da obra inaugurou ainda o Projeto Viva Jardim São Benedito, o qual visa a promoção de shows com artistas locais no segundo domingo de cada mês, das $11 \mathrm{~h}$ às $13 \mathrm{~h}$, de modo a incentivar a ida das famílias à praça.

Segundo reportagem de 2018 do site da Prefeitura de Campos dos Goytacazes, devido ao sucesso do projeto, o objetivo para 2019 seria o de aumentar a quantidade de eventos no Jardim São Benedito (NUNES, 2018). 0 Viva Jardim São Benedito consiste em apresentações intimistas de voz e violão, nos ritmos MPB, Pop Rock, Blues e Jazz, realizadas por músicos que se inscrevem em um edital aberto pela superintendência responsável (NUNES, 2018).

Também no Jardim São Benedito, acontece a Feira Economia, Trabalho e Cultura (Feira ETC), na qual expositores comercializam artesanatos, doces, produtos da agricultura familiar, entre outros, todos os domingos das $9 \mathrm{~h}$ às 16h. Tanto o Viva Jardim quanto a Feira ETC fazem parte do projeto de revitalização do Jardim São Benedito (JORNAL TERCEIRA VIA, 2018).
No final de 2018, teve início a revitalização da Praça das Taças, no Parque Alberto Sampaio, a partir de uma ação conjunta da Secretaria Municipal de Desenvolvimento Ambiental, Secretaria Municipal de Infraestrutura e Mobilidade Urbana, Companhia de Desenvolvimento do Município de Campos dos Goytacazes (Codemca) e Superintendência de Limpeza Pública. De acordo com o site da Prefeitura Municipal de Campos dos Goytacazes (NUNES, 2018), as intervenções incluiriam pintura, reforma dos canteiros, estudo para reativação do chafariz e retirada das grades com a intenção de que a comunidade pudesse transitar pelo espaço, dando movimentação à área central da cidade.

É válido ressaltar que a Praça das Taças já havia sido contemplada, em 2012, por um projeto paisagístico, que fazia parte de um projeto de revitalização da área central da cidade. Em período semelhante, em 2011, a Praça Nilo Peçanha, no Jardim São Benedito, também recebeu o novo projeto de paisagismo e recuperação de praças, jardins e canteiros do município. 0 local foi revitalizado com o plantio de cerca de seis mil mudas de plantas ornamentais.

Além das obras realizadas em algumas praças, notam-se também algumas ações do governo de incentivo ao uso das praças. O Projeto Praça Viva, por exemplo, desenvolvido pela Superintendência de Entretenimento e Lazer, em parceria com a Associação dos Profissionais de Educação Física (Apef) e o Institutos Superiores de Ensino do Censa (Isecensa), tem o objetivo de proporcionar qualidade de vida e bem-estar por meio de atividades físicas a todos os cidadãos. 0 projeto já foi iniciado nas praças do Parque Santo Amaro, Parque Guarus, Pecuária, Flamboyant, IPS, Jardim Carioca, Jóquei e Morro do Coco (BARRETO, 2017).

\section{Os seus sonhos não podem esperar}


Ainda nesse sentido, em 2018, foi aprovado o Projeto de Lei $n^{0}$ 0130/18, o qual colocou o projeto Samba na Praça, que acontece no Jardim do Liceu, no calendário oficial do município (CHAGAS, 2018). 0 Samba na Praça acontece sempre no primeiro domingo de cada mês e chega a reunir mais de duas mil pessoas por edição. "A iniciativa é de cantores e instrumentistas da cidade que sentiam a necessidade de se encontrar para tocar e cantar apenas como confraternização" (TRINDADE, 2018).

Após as análises realizadas, concluiu-se que, no governo Rosinha Garotinho, as ações voltadas às praças do município são realizadas pela própria prefeitura, e consistem primordialmente em obras de revitalização de praças já existentes, mas contemplam também a construção de algumas delas. Além disso, nota-se uma grande heterogeneidade de praças e bairros atendidos, observando-se, no entanto, uma tendência de maior atenção aos bairros cuja população é mais carente. Também destaca-se o grande quantitativo de praças citadas ao longo das reportagens, as quais foram beneficiadas por projetos da prefeitura, o que possivelmente reflete um momento de maior abundância do governo.

0 governo de Rafael Diniz apresenta algumas semeIhanças com o da ex-prefeita, Rosinha Garotinho, entretanto, os pontos divergentes aparecem em maioria. Assim como na gestão anterior, o atual prefeito também tem realizado algumas obras de revitalização de praças existentes, contudo, até o momento, não foram encontrados relatos de novas construções. Por outro lado, foram identificadas ações de incentivo ao uso de tais espaços livres públicos, como é o caso do Projeto Praça Viva e da Feira ETC. Outro ponto que difere do governo Rosinha Garotinho consiste na opção pela realização de parcerias público-privadas, o que fica claro, por exemplo, no programa Adote uma Praça. Tal alternativa, pode estar relacionada ao momento atual de menor abundância do governo, que se reflete, ainda, no quantitativo de praças beneficiadas até o momento, bastante inferior ao observado no governo anterior. Além disso, nota-se uma menor heterogeneidade de praças e bairros contemplados, fazendo-se perceber uma maior atenção às praças principais, localizadas na região central da cidade. Desse modo, principalmente no governo Rafael Diniz, até o presente momento, percebe-se que os investimentos não têm-se dado de forma homogênea e igualitária em toda a cidade, sendo realizados de forma seletiva e intencional em determinadas áreas privilegiadas.

De modo geral, constata-se que ambos os governos realizam ou realizaram algumas ações, projetos ou programas voltados às praças da cidade, contudo, não se observa um planejamento ou a constituição de políticas públicas consistentes que possam, de fato, suprir de forma igualitária a deficiência de espaços livres públicos de qualidade voltados ao lazer. Além disso, deve-se ressaltar a importância de políticas complementares, como a de transporte público de qualidade, que garantam a acessibilidade a tais espaços.

\section{Conclusões}

Conforme destacado neste artigo, as praças são espaços livres públicos de suma importância para as cidades e os seus moradores sob os mais variados aspectos. São palco de acontecimentos cotidianos e insólitos, foco de interesses diversos e muitas vezes contraditórios, e expressam em si uma multiplicidade de significados, histórias, anseios e conflitos. Sendo reflexo das transformações vivenciadas pela sociedade, acabam incorporando processos que atingem a cidade como um todo, o que gera consequências na forma como a população se relaciona com elas e entre os próprios grupos que a compõem. Tendo em vista o contexto apresentado, buscou-se analisar de que modo o planejamento, ou a falta dele, tem influenciado tais fenômenos e, inclusive, a construção da paisagem urbana da cidade.

Neste sentido, por meio dos estudos realizados, observou-se que o planejamento parece falhar em alguns pontos, desdobrando-se em consequências negativas que, no entanto, podem ser revertidas através da percepção da importância de tais espaços e do estabelecimento de um enfoque sobre eles. 0 levantamento das praças existentes atualmente em Campos dos Goytacazes, em conjunto com a identificação de sua localização através de um mapa, explicitou a presença de um número significativo desta tipologia 
de espaço livre público; no entanto, percebeu-se que a sua distribuição ao longo da malha urbana denota a inexistência de um estudo aprofundado em relação às características e demandas dos bairros. Desse modo, enquanto em algumas áreas nota-se a concentração de praças, em outras, não há nenhuma. É importante ressaltar que acredita-se que a distribuição das praças não deve reforçar a fragmentação da cidade e a segregação da população, ou seja, julga-se interessante o estímulo ao deslocamento para uso de espaços livres públicos pertencentes a outros contextos, diferentes do local onde se reside; entretanto, há que se fazer um planejamento nesse sentido, garantindo a complementariedade entre os espaços e a composição de um sistema. Nesse contexto, contudo, a promoção da conectividade e das possibilidades adequadas de acesso se fazem imprescindíveis.

Sob esta ótica, a tendência de homogeneização dos espaços pode tornar-se um empecilho, tendo em vista que muitas praças da cidade acabam tendo um programa de necessidades extremamente parecido, sem potencial para gerar estímulos no sentido de que a população em geral tenha interesse em percorrê-los e utilizá-los. Além disso, tal percepção sugere a inexistência de um estudo visando compreender as potencialidades e limitações dos espaços e, especialmente, os anseios da população. Diante deste cenário, foram observadas situações como praças com área muito reduzida e estrutura precária; com implantação de equipamentos superiores ao que seu espaço físico é capaz de abranger adequadamente; apresentando estruturas muito semelhantes e repetitivas; entre outros aspectos que coadunam para uma sensação de que, muitas vezes, praças são construídas apenas por sua existência em si, sem a preocupação se serão locais atrativos e que possibilitem um uso efetivo.

Ainda no que tange ao âmbito do planejamento, percebeu-se uma dificuldade generalizada de garantir a manutenção e preservação das praças de Campos dos Goytacazes, que pode ser relacionada, entre outros fatores, a um custo elevado em função do quantitativo levantado. Frente a esta questão, nota-se que, por vezes, se fazem presentes investimentos seletivos voltados para determinadas áreas de interesse, os quais podem variar em função do momento e de objetivos específi- cos. Cabe destacar que manter as boas condições dos espaços livres públicos é importante não apenas para viabilizar seu uso mas, de forma mais ampla, para garantir a sensação de segurança a partir do movimento constante de pessoas - que contribui para que usos indevidos sejam inibidos - e para a manutenção da própria vida nas cidades, bem como o incentivo à constituição da esfera de vida pública.

Nesse sentido, as políticas de incentivo ao uso de tais espaços também podem tornar-se ótimas soluções. A exemplo disso, foram destacadas o "Samba na Praça", a "Feira ETC", o "Viva Jardim São Benedito", o "Projeto Praça Viva" como iniciativas extremamente interessantes, as quais acredita-se que deveriam espalhar-se por outras praças da cidade no intuito de fortalecer ainda mais a relação entre a população e os espaços livres públicos. 


\section{Referências}

ABREU, Frânio. Inaugurações marcam os 179 anos de Campos dos Goytacazes. Campos dos Goytacazes: Prefeitura Municipal de Campos dos Goytacazes, 2014. Disponível em: https://www.campos.rj.gov.br/exibirNoticia.php?id_noticia=24010. Acesso em: 07 jan. 2019.

ALIPRANDI, Danielly Cozer. $\mathbf{O}$ sistema de espaços livres da cidade de Campos dos Goytacazes/RJ: carências e potencialidades. 2017. Tese (Doutorado em Arquitetura) - Faculdade de Arquitetura e Urbanismo, Universidade Federal do Rio de Janeiro. Rio de Janeiro: 2017.

ALVAREZ, Isabel Pinto. A produção e reprodução da cidade como negócio e segregação. In: CARLOS, Ana Fani; VOLOCHKO, Danilo; ALVAREZ, Isabel Pinto (orgs.). A cidade como negócio. São Paulo: Editora Contexto, 2015. p. 65-80.

ASSIS, Taysa. Praça do IPS elogiada pelos moradores. Campos dos Goytacazes: Prefeitura Municipal de Campos dos Goytacazes, 2012. Disponível em: https://www.campos.rj.gov.br/exibirNoticia.php?id_noticia=15254. Acesso em: 08 jan. 2019.

BARRETO, Liliane. Projeto Praça Viva abre inscrições nesta $\mathbf{2}^{\mathbf{a}}$ para atividades físicas. Campos dos Goytacazes: Prefeitura Municipal de Campos dos Goytacazes, 2017. Disponível em: https://www.campos.rj.gov.br/exibirNoticia.php?id_noticia=39422. Acesso em: 08 Jan. 2019.

CAMPOS DOS GOYTACAZES. Lei $\mathbf{n}^{\mathbf{0}} \mathbf{7 . 9 7 2}$, de 10 de Dezembro de 2007. Institui o Plano diretor do Município de Campos dos Goytacazes. Disponível em: https://leismunicipais.com.br/a1/plano-diretor-campos-dos-goytacazes-rj. Acesso em: 06 jan. 2019

CAMPOS DOS GOYTACAZES. Lei $\mathbf{n}^{\mathbf{0}} \mathbf{7 . 9 7 4}$, de 10 de Dezembro de 2007. Institui a Lei de Uso e Ocupação do Solo Urbano do Município de Campos dos Goytacazes. Disponível em: https://leismunicipais.com.br/a1/plano-de-zoneamento-uso-e-ocupacao-do-solo-campos-dos-goytacazes-rj. Acesso em: 06 jan. 2019

CAMPOS DOS GOYTACAZES. Lei $\mathbf{n}^{\mathbf{0}} \mathbf{7 . 9 7 5}$, de 12 de Dezembro de 2007. Institui a Lei de Parcelamento do Solo do Município de Campos dos Goytacazes. Disponível em: https://leismunicipais.com.br/a1/parcelamento-do-solo-campos-dos-goytacazes-rj. Acesso em: 06 jan. 2019.

CAMPOS DOS GOYTACAZES. Lei $\mathbf{n}^{\mathbf{0}} \mathbf{8 . 7 7 1}$, de $\mathbf{3 0}$ de Agosto de 2017. Dispõe sobre o Programa Adote uma Praça, no Município de Campos dos Goytacazes e dá outras providências. Disponível em: https://leismunicipais.com.br/a1/rj/c/campos-dos-goytacazes/lei-ordinaria/2017/878/8771/lei-ordinaria-n-8771-2017-dispoe-sobre-o-programa-adote-uma-praca-no-municipio-de-campos-dos-goytacazes-e-da-outras-providencias?q=Lei\%208771. Acesso em: 06 jan. 2019

CARLOS, Ana Fani Alessandri. A condição espacial. São Paulo: Contexto, 2011.

CHAGAS, Viviane. Aprovada lei que coloca Projeto Samba na Praça do Liceu no Calendário Oficial do Município. Campos dos Goytacazes: Câmara Municipal de Campos dos Goyatacazes, 2018. Disponível em: http://www.camaracampos.rj.gov.br/legislativo/1499-aprovada-lei-que-coloca-projeto-samba-na-praca-do-liceu-no-calendario-oficial-do-municipio. Acesso em: 15 jan. 2019.

FARIA, Teresa Peixoto. Configuração do espaço urbano da cidade de Campos dos Goytacazes, após 1950: novas centralidades, velhas estruturas. In: Congresso de Geógrafos da América Latina, 10. 2005.

FARIA, Gislanne. Prefeitura constrói e reforma praças. Campos dos Goytacazes: Prefeitura Municipal de Campos dos Goytacazes, 2010. Disponível em: https://www.campos.rj.gov.br/exibirNoticia.php?id_noticia=1930. Acesso em: 07 de jan. 2019.

FILHO, Telmo. Mais duas praças inauguradas nesta quarta-feira. Campos dos Goytacazes: Prefeitura Municipal de Campos dos Goytacazes, 2013. Disponível em: https://www.campos.rj.gov.br/exibirNoticia.php?id_noticia=17242. Acesso em: 08 jan. 2019.

FILHO, Telmo. Praça do Morar Feliz do Esplanada será inaugurada neste sábado. Campos dos Goytacazes: Prefeitura Municipal de Campos dos Goytacazes, 2015. Disponível em: < https://www.campos.rj.gov.br/exibirNoticia.php?id_noticia=32268>. Acesso em: 08 jan. 2019.

HARVEY, David. A produção capitalista do espaço. São Paulo: Annablume, 2005.

MARIA, Kelly. Praças e jardins da cidade estão ganhando novo visual. Campos dos Goytacazes: Prefeitura Municipal de Campos dos Goytacazes, 2013. Disponível em: https://www.campos.rj.gov.br/exibirNoticia.php?id_noticia=19573. Acesso em: 08 jan. 2019.

MARICATO, Ermínia. As ideias fora do lugar e o lugar fora das ideias: planejamento urbano no Brasil. In: ARANTES, Otília; VAINER, Carlos; MARICATO, Ermínia. A cidade do pensamento único: desmanchando consensos. Petrópolis: Editora Vozes, 2002. p. 121-188.

NUNES, Livia. Viva Jardim São Benedito: músicos podem se inscrever até 6ª . Campos dos Goytacazes: Prefeitura Municipal de Campos dos Goytacazes, 2018. Disponível em: https://www.campos.rj.gov.br/exibirNoticia.php?id_noticia=46407. Acesso em: 15 jan. 2019. 
SANCHEZ, Fernanda. Políticas urbanas em renovação: uma leitura crítica dos modelos emergentes. Revista brasileira de estudos urbanos e regionais, Rio de Janeiro, n. 1, 1999, p. 115-132. Disponível em: http://rbeur.anpur.org.br/rbeur/article/view/13/1. Acesso em: 15 nov.2018.

SANT'ANNA, Aline Guimarães de Souza. As praças e os conteúdos das desigualdades socioespaciais urbanas em Campos dos Goytacazes - RJ. 2017. Dissertação (Mestrado em Geografia) - Universidade Federal Fluminense, Campos dos Goytacazes, 2017.

THEDERICH, Kelly. Campos Luz ilumina praça praças de Campos. Campos dos Goytacazes: Prefeitura Municipal de Campos dos Goytacazes, 2011. Disponível em: https://www.campos.rj.gov.br/exibirNoticia.php?id_noticia=8451. Acesso em: 09 jan. 2019.

TRINDADE, Ocinei. Samba na Praça volta domingo ao Jardim do Liceu. Jornal Terceira Via, Campos dos Goytacazes, 12 abr. 2018 . Disponível em: https://www.jornalterceiravia.com.br/2018/04/12/samba-na-praca-volta-domingo-ao-jardim-do-liceu/. Acesso em: 15 jan. 2019. 